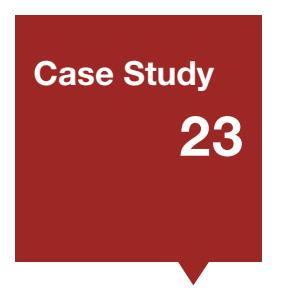

\title{
Surveying your level of preparation for Research Data Management
}

\author{
Authors: Ignasi Labastida (Head of the Research Unit at the Learning \\ and Research Resources Centre [CRAI] of the University of Barcelona) \& \\ Paul Ayris - Pro-Vice-Provost (UCL Library Services), Co-Chair of the LERU \\ INFO Community (League of European Research Universities) \& Adviser to \\ the LIBER Board (Association of European Research Libraries)) \\ Email: ilabastida@ub.edu / p.ayris@ucl.ac.uk
}

\section{learn}

\section{SURVEY: Is your institution ready for managing research data?}

The LEARN project has compiled the following survey as a self-assessment tool to assist institutions discover how ready they are for managing research data. The survey is based on the issues posed to institutions by the LERU Roadmap for Research Data published at the end of 2013, and available at: http://www.leru.org/files/publications/AP14_LERU_Roadmap_for_Research_data_final.pdf.

The survey has thirteen questions addressing the main elements to be taken into account in developing an institutional strategy for research data management. Each question has three possible answers represented by green, yellow or red answers. The more 'green light' responses recorded, the readier an institution probably is for managing its research data. We encourage you to complete the questionnaire online which is available at: http://learn-rdm.eu/en/rdm-readiness-survey/, with a link straight through to the questionnaire at http://goo.gl/forms/m6PGJ34tGr. The survey is available in both English and Spanish.

The Survey is iterative, in that it can (once taken) be re-taken at regular intervals. Changes in the scores will themselves illustrate the level of progress made in the intervening period. 
My institution has a policy on research data

My institution is working on a policy on research data

My institution has no policy regarding research data

\section{LEADERSHIP}

My institution has a steering committee on research data

My institution is working ion setting up a working group to develop services and policies on

research data

There is no dedicated group on research data at my institution

\section{ROLES}

My institution has established new roles to steward the management of research data

Some staff are shifting part of their work to involve the management of research data

There is no one dedicated to research data

\section{INFORMATION (SERVICES)}

My institution has an information point/helpdesk/webpages on research data management

There is someone at/in the university library/research office who can give advice on research data

management to researchers

- No service at my institution provides clear information on research data management

\section{DISSEMINATION (AWARENESS)}

My institution has created some materials on the management of research data

There are some links with information on research data on the library/research office website

Researchers need to look outside my institution for information on the management of research data

\section{INFRASTRUCTURE}

My institution provides an infrastructure to manage research data through the complete research cycle My institution provides some services for managing data but not through the complete research cycle

Researchers need to use external facilities to manage their data

\section{COST MODEL}

My institution has established a list of free and paid for services based upon an analysis of costs

My institution offers some services for free and some need to be paid but there is not a public list of paid services

There has not been any analysis regarding the cost of managing research data at my institution
There is a protocol to define who is the owner of research data produced

My institution has a policy on intellectual property rights (IPR) but there is no mention of research data

My institution does not have a policy on IPR

\section{SELECTION OF DATA}

There are protocols, laid down by bodies such as the university or the research funder, to define which data has to be kept, shared, archived, etc

My institution gives some advice about the preservation of research data

My institution has not established any guidance about which research data should be kept

\section{PUBLICATION AND SHARING}

There are protocols, laid down by bodies such as the university or the research funder, defining which data has to be published, where and under which terms of use

My institution allows researchers to publish research data in our institutional repository or in a disciplinary repository (outside the institution)

My institution does not have a protocol or a place to publish research data

\section{TRAINING}

My institution has scheduled regular training sessions on research data management addressed to researchers, students and staff

My institution offers training sessions in research data management upon demand

There are no training sessions about how to manage research data

\section{REVISION AND UPDATES}

My institution has established a roadmap to review and, if needed, update its policy and services on research data

My institution is developing services for managing research data, but there is no scheduled calendar

for reviews

My institution has yet to start the conversation to create a working group on research data

13. OPEN DATA

My institution publishes research data openly by default and it has established a set of exceptions to waive this policy

My institution allows researchers to share data openly but there is no formal policy established

My institution does not publish any data openly

This proiect has received funding from the European Union's Horizon 2020

research and innovition program for under grapean Union's Horizon 2020 